\title{
Assessing Preoperative Hope and Expectations Related to Functional Neurosurgery: A New Questionnaire
}

Michalina Radomska ( $\nabla$ michalina.radomska@etu.unige.ch )

University of Geneva

Joao Flores Alves dos Santos

Geneva University Hospitals

Kerstin Weber

Geneva University Hospitals

Marc Baertschi

University of Lausanne

Pierre R. Burkhard

Geneva University Hospitals

François Herrmann

Geneva University Hospitals

Sanaâ Belayachi

University of Liège

Nicolas Favez

University of Geneva

Alessandra Canuto

Geneva University Hospitals

\section{Research Article}

Keywords: Epilepsy surgery, Deep brain stimulation, Preoperative expectations, Hope, Questionnaire.

Posted Date: May 25th, 2021

DOl: https://doi.org/10.21203/rs.3.rs-558755/v1

License: (c) (i) This work is licensed under a Creative Commons Attribution 4.0 International License. Read Full License

Version of Record: A version of this preprint was published at BMC Psychology on March 4th, 2022. See the published version at https://doi.org/10.1186/s40359-022-00766-z. 

1 Assessing Preoperative Hope and Expectations Related to Functional Neurosurgery: A New

2 Questionnaire.

3

4 Michalina Radomska ${ }^{1}$, Joao Flores Alves dos Santos $^{2}$, Kerstin Weber ${ }^{2}$, Marc Baertschi ${ }^{3}$, Pierre R.

5 Burkhard ${ }^{2}$, François Herrmann ${ }^{2}$, Sanaâ Belayachi ${ }^{4}$, Nicolas Favez ${ }^{1}$, and Alessandra Canuto ${ }^{2}$

6

7 michalina.radomska@etu.unige.ch

$8 \quad$ joao.floresalvesdossantos@hcuge.ch

$9 \quad$ kerstin.weber@hcuge.ch

10 marc.baertschi@unil.ch

11 pierre.burkhard@hcuge.ch

12 francois.herrmann@hcuge.ch

13 sanaa.belayachi@uliege.be

14 nicolas.favez@unige.ch

15 alessandra.canuto@hcuge.ch

16

17 Correspondence concerning this article should be addressed to Michalina Radomska

18 michalina.radomska@etu.unige.ch

19

$20 \quad{ }^{1}$ University of Geneva, Switzerland

$21{ }^{2}$ Geneva University Hospitals, Switzerland

$22{ }^{3}$ University of Lausanne, Switzerland

$23{ }^{4}$ University of Liège, Belgium 


\section{Abstract}

Background: Despite successful functional neurosurgery, patients suffering from epilepsy or Parkinson's disease may experience postoperative psychological distress and social maladjustments. Difficulties in coping with postoperative changes, even positive ones, have shown to be related to patients' presurgery cognitive representations (i.e., expectations, hope, abstract vs. concrete representations). The aim of this study was to develop an instrument assessing various key features of surgery outcomes' representations, namely the Preoperative Hope and Expectations Questionnaire, PHEQ.

Methods: Participants were patients $(n=50)$ diagnosed with Parkinson's disease $(n=25)$ or epilepsy $(n=25)$, candidates for functional neurosurgery (i.e., Deep brain stimulation, anterior temporal lobectomy). At 2-3 weeks before the planned surgery, they were administrated items assessing their actual state, preoperative expectations, and hope regarding surgery outcomes. They also completed measures assessing optimism, quality of life and mood.

Results: Exploratory analysis resulted in a 16-item version of the PHEQ composed of two factors (abstract representations, including psychological well-being and concrete representations, such as functional aspects of everyday functioning). The PHEQ demonstrated high internal consistency and good convergent validity. Patients were more prone to express postoperative improvements in terms of hope rather than expectations. They generally focused on concrete rather than abstract features, although patients with Parkinson's disease had higher abstract future-oriented representations.

Conclusions: The PHEQ presents satisfactory psychometric properties and may be considered as a reliable instrument for research and clinical practice.

\section{Keywords}

Epilepsy surgery, Deep brain stimulation, Preoperative expectations, Hope, Questionnaire. 


\section{Background}

Bilateral subthalamic nuclei deep brain stimulation (DBS) is known to reduce motor symptoms as well as dopaminergic-related complications in advanced Parkinson's disease (PD)

(Weaver et al., 2005). While successful functional neurosurgery leading to the sudden alleviation

of symptoms is expected to significantly improve patients' quality of life (QOL), growing evidence suggest that such positive effect is questionable (Agid et al., 2006; Bell et al., 2011;

Gilbert, 2012; Schüpbach et al., 2006). This phenomenon has been well documented in surgical treatment of medically intractable epilepsy. More specifically, despite successful anterior temporal lobectomy (ATL) and alleviation of seizures, some patients experience postoperative psychological and socio-professional maladjustments (e.g., difficulties discarding sick role behaviors $^{1}$, family dysfunctions, occupational disabilities), leading to major deterioration in their postoperative QOL (e.g., Wilson, 2001; Wilson et al., 2007). In order to account for such peculiar phenomena, the concept of "burden of normality" (BON) syndrome has been proposed (Bladin, 1992; Wilson, 2001; Wilson et al., 2007). According to the BON model, successful life changing medical intervention gives rise to an evolving process of postoperative psychological and social adjustments. This process may depend on patients' propensity to switch from roles and selfrepresentations from "chronically ill" to "healed". In this prospect, future-oriented cognitions, such as hope and expectations regarding surgery outcomes, has been suggested to play a key role in postoperative psychosocial adjustment process.

Hope and expectation can be defined as beliefs about the consequences of engaging in treatment (Constantino et al., 2011). Such preoperative projections have been significantly related to the success of rehabilitation (e.g. Albrecht \& Higgins, 1977), to the level of postoperative

\footnotetext{
${ }^{1}$ Behaviors associated with being sick such as domestic, social, recreational, vocational underactivity or focusing on novel somatic or cognitive complaints.
} 
functional recovery (e.g., Mondloch et al., 2001; Taenzer et al., 1986) and to postoperative QOL (e.g. Gonzalez Saenz de Tejada et al., 2010). In the particular case of candidates for functional neurosurgery, unrealistic expectations might play a pivotal role in postoperative dissatisfaction and adverse psychosocial outcomes (e.g., Baxendale \& Thompson, 1996; Rose et al., 1995). Additionally, unspecific (e.g., being normal, feeling like myself again) or excessively high expectations have been connected to an increased postoperative psychological distress and a general dissatisfaction with surgery outcomes (e.g., Gilbert, 2012; Maier et al., 2013; Wilson et al., 1999). High expectations may further reduce patient's ability to accept less successful outcomes, as well as his capacity to face psychological and social changes brought about by functional neurosurgery (Bell et al., 2010).

Numerous studies have explored preoperative expectations of patients candidates for DBS or ATL (see Table 1). Nevertheless, these studies vary widely in conceptual and methodological approaches, ranging from qualitative design with structured or semi-structured interviews (e.g., Maier et al., 2013; Törnqvist et al., 2007; Wheelock et al., 1998; Wilson et al., 1998) to ad hoc questionnaires (e.g., Baca et al., 2009; Reddy et al., 2014; Rose et al., 1995), and only a few studies have used validated instruments (e.g., Mancuso et al., 2001, 2002; Salgado et al., 2008). Some studies have provided a modified satisfaction scale or modified standard measures of symptoms used as an expectation scale (Hasegawa et al., 2014; Nisenzon et al., 2011), in which patients are asked to rate for each question the current symptom severity (e.g. ranging from no problem to severe problem) and the expectation for change after treatment (e.g. ranging from expected to be very much worse to expected to be very much improved). However, the transferability of dimensions from satisfaction or functional state to the measurement of expectations has received limited justification. 
Furthermore, most studies have failed to make a distinction between hope and expectation, while they are in fact linked but distinct constructs. Both seem to pertain to general construct of dispositional optimism (Leung et al., 2009). However, Uhlmann et al., (1984) highlighted an important distinction between expectation (probabilistic beliefs that something will happen) and hope (desire that the specific outcome would occur). More specifically, they suggested that patients' expectations and hope pertain to two distinct perceptual dimensions: expectancy and value. Expectancy primarily reflects a perception that the occurrence of a given outcome is likely. Patients' hope, in contrast to expectations, primarily reflect a valuation, a perception that a given outcome is desired. An outcome may be wanted but not expected (e.g. I hope my disease will be cured, but I do not expect that) or, inversely, expected but not desired (e.g. I expect to receive, but do not want, a painful injection). More recent studies further suggested to differentiate probability expectations (rational projections) and idealized expectations (or hopes) in exploring patients' expectations in clinical trials (Sherman et al., 2014). In their study based on cognitive interviews, patients defined hope as what they wished for or wanted to occur at the highest levels of aspiration, unconstrained by reality, prior knowledge or experience, and expectations as the most realistic projections of what might happen based on prior experience and illness history. This distinction was consistent across participants.

To sum up, patients' future-oriented cognition constitutes an important determinant of clinical outcomes following functional neurosurgery. Discrepancies between anticipated outcome and postsurgical reality, even in the case of significant symptoms reduction, may yield to disappointment and psychosocial maladjustments (Montel \& Bungener, 2009). Although several tools have been proposed to explore preoperative representations of patients candidates for DBS or ATL, the nature of such representations (expectation vs. hope) and their content (concrete vs. abstract) failed to be assessed properly. The aim of the present study was to develop an 
instrument assessing the various key features of prior representations related to surgery outcomes, namely the Preoperative Hope and Expectation Questionnaire (PHEQ). More specifically, items were generated by assessing patients' hope and expectations regarding postoperative improvements across abstract (e.g. psychological well-being) and concrete (e.g. symptoms reduction) life domains. The factor structure and internal consistency of the PHEQ were then evaluated. The external validity of the final version of the PHEQ was assessed by examining its relationships with measures of optimism, mood, mental and physical QOL. A high level of hope and expectations was expected to be correlated to dispositional optimism and negatively correlated to anxio-depressive symptoms (Alarcon et al., 2013). Additionally, concrete hope and expectations were expected to be specifically connected to physical QOL, while abstract hope and expectations to mental QOL. Finally, this study aimed to explore whether preoperative future-oriented representations vary according to the type of functional neurosurgery (DBS vs. ATL).

\section{Materials and Methods}

\subsection{Participants and procedure}

Patients diagnosed with PD or epilepsy and potential candidates for functional neurosurgery were recruited from the University Hospitals of Geneva in Switzerland. Inclusion criteria were a DBS or epilepsy surgery medical indication established by neurologist, neurosurgeon, psychiatrist and neuropsychologist. The main selection criteria for DBS surgery were disabling motor complications of dopaminergic treatment, the absence of dementia (based on a cutoff score of 130 on the Mattis Dementia Rating Scale), and severe depression with suicidal ideations. Motor symptoms were assessed before surgery using the Unified Parkinson's Disease Rating Scale III (UPDRS III, Fahn \& Elton, 1987). The selection for ATL was a thorough procedure aimed at identifying potential candidates for surgery by determining the risk- 
142 benefit ratio for each patient. Patients clinically accepted for DBS or epilepsy surgery were

143 invited to participate in the present study. They were selected from the French speaking 144 community since self-administered questionnaires are in French. Based on these criteria, 50

145 patients (32 males and 18 females) aged between 18 and 73 (Mean of overall sample: 46.16 146 years, $S D=17.05)$ were selected for the present study. Twenty-five patients with PD (17 men 147 and 8 women; mean age: 59.60 years, $S D=7.41$ ) were candidates for $\mathrm{DBS}$, and 25 patients with 148 epilepsy (15 men and 10 women; mean age: 32.72 years, $S D=12.75)$ were candidates for ATL. Informed consent was obtained from all participants following a full explanation of the experimental procedure. Detailed written and oral instructions explained that participants would be asked questions about different aspects of their everyday life as well as regarding their programmed neurosurgery. They were participating on a voluntary basis. At 2-3 weeks before the planned intervention, participants completed all the measures described below, which were counterbalanced.

\subsection{Materials}

\subsubsection{The Preoperative Hope and Expectation Questionnaire (PHEQ)}

The process by which the PHEQ has been developed was described in the present section. Psychometric properties of the PHEQ (factorial structure, internal consistency and convergent validity) were reported in the Results section (see Section 3).

Item selection. A qualitative review of studies exploring preoperative expectations on

DBS and ATL populations by means of questionnaires, interviews and semi-structured interviews was conducted (see Table 1). This review first revealed that preoperative expectations relate to four distinct life domains: (1) physical and mental state; (2) autonomy in daily living activities; (3) psychological and emotional well-being; and (4) social-relational life. Based on these features, an initial pool of 24 items has been generated. All items consisted in affirmations 
regarding the above-mentioned life domains. Any disease-specific reference (e.g., tremor, stiffness, dyskinesia, freezing, dystonia, fatigue, seizures, etc.) has been systematically replaced by the general term of reduction of symptoms. It is worth noticing that expectation and hope, which are in fact two distinct concepts (Uhlmann et al., 1984), appeared to be mixed up in previous measures. Thus, in order to examine expectation and hope separately, each item has been framed in the context of realistic expectations (e.g. Regarding physical pain, I realistically expect...) and in the context of hope/desire (e.g. Regarding physical pain, I really hope for...), and rated on a 5-point scale $(0=$ no improvement at all to $4=$ total improvement or symptom relief). Additionally, each item has been assessed regarding actual state (e.g. I have physical pain $)$, by means of a 5 -point scale $(0=$ not at all to $4=$ extremely).

\section{Qualitative evaluation of the initial pool of item. Three judges (a neurologist, a} psychiatrist and a neuropsychologist), who were familiar with the concept of preoperative expectations, were asked to rate the level of clarity and consistency of each item. Based on the judges' evaluation, 6 items were discarded as they appeared irrelevant (pregnancy concerns, others' worries, new activities, economic worries, general health improvement, risk of injury), 4 items were replaced by 2 more general items (the item To be able to participate in leisure activities included sports, travel, etc.; the item To be able to work, included professional activity, housework, etc.). Additionally, 4 new items were generated based on experts' proposals in order to explore more precisely issues frequently reported by patients in clinical settings (physical appearance, ability to enjoy life, feeling comfortable in social situations, achieve projects). The new 20-item form was then administered to 10 candidates for DBS $(n=5)$ and ATL $(n=5)$. A free response section was included at the end of the questionnaire allowing respondents to write down any additional expectation that did not appear in the PHEQ. Based on patients' responses, two new items were added (To feel more like myself and To be like everyone else). 
The PHEQ. Based on experts and patient's evaluation of the initial pool of item, a

preliminary version of the PHEQ comprised 22 items (see Table 3), assessing preoperative expectation and hope varying in level of abstraction (11 items expected to assess abstract hope and expectations and 11 items expected to assess concrete hope and expectations). The questionnaire was presented in 3 parts, each item has been rated regarding the following conditions: (a) the current state (Actual State, AS), (b) patients' realistic prediction of outcomes (Preoperative Expectations, PE), and (c) patients' wishes or desires concerning surgery outcomes (Preoperative Hope, PH). Six items are reverse-scored in PHEQ AS scale (i.e., items 2, 12, 19, 20, 21 and 22). For each PHEQ measure, scores are summed, so that high scores on PE and PH measures indicate an increased tendency to have high expectations and high hope regarding postoperative QOL improvements, while high scores on AS measures indicate better selfevaluation of current physical, mental, psychological and relational life.

\subsubsection{Other measures}

Quality of life. The French version of the Medical Outcome Study Short Form (MOS-SF36; Leplège et al., 1998) was administered in order to assess patients' subjective QOL. This selfreport measure consists of 36 questions about QOL and care outcomes. It evaluates eight dimensions, including the Physical Component Summary score (PCS) and the Mental Component Summary score (MCS). Each subscale's scores range from 0 (worst condition) to 100 (best condition). In the present study, Cronbach's alphas indicate excellent internal consistency for the PCS (.94) and the MCS (.91) measures.

Dispositional optimism. The French version of the Life Orientation Test Revised (LOT, Trottier et al., 2008) was administered in order to assess dispositional optimism. This scale consisted of 10 items, rated on a 5-point scale $(0=$ strongly agree to $4=$ strongly disagree $)$, assessing the persons' expectations regarding the favorability of future outcomes (e.g., In 
uncertain times, I usually expect the best). The dispositional optimism is a personality characteristic relatively stable across time. In the present study, Cronbach's alpha indicates acceptable internal consistency for the LOT-Optimism measure (.78).

Mood. The French version of the Hospital Anxiety and Depression Scale (HADS, Zigmond \& Snaith, 1983) was administrated in order to examine participant's mood status. The HADS is composed of 14 items measuring anxiety and depression symptoms. Participants had to determine to what extent the situation described in each particular statement applied to them during the last 7 days, using a 4 -point scale $(0=$ not at all; $3=$ extremely $)$. Seven items assess the respondents' state of depression (HADS-D), while the 7 remaining items constitute a selfreported measure of general anxiety (HADS-A). In the present study, Cronbach's alphas indicate good to acceptable internal consistency for the HADS-A (.85) and HADS-D (.78) measures.

\subsection{Statistical analyses}

Exploratory factor analysis was performed to select items according to their level of abstraction (concrete vs. abstract). The correlation matrix was analyzed with an EFA computed with two factors, using the maximum likelihood method. The Kaiser-Meyer-Olkin (KMO) method was used to measure sampling adequacy, and Bartlett's test of sphericity was computed to test the null hypothesis that the variables in the correlation matrix are uncorrelated. A KMO between .50 and 1.0 and a significant Bartlett's test of sphericity are considered appropriate for factor analysis (Kline, 2014). Considering the small size of the sample, EFA has been conducted by means of Bayesian estimations (Lee \& Song, 2004), using the JASP software. The reliability of each PHEQ measure was then examined with Cronbach's alpha. Convergent validity has been explored by means of Pearson's correlations and regression analyses. Finally, future oriented cognitions were explored across the two groups of patients by means of a mixed-design ANOVA. 


\section{Results}

Descriptive statistics for the entire sample and for each group of patients on all the variables of interest are reported in Table 2 . The two groups of patients differed on age $\left(t_{48}=-9.12\right.$, $p<.001)$, physical QOL $\left(t_{43}=-6.73, p<.001\right)$ and disease duration $\left(t_{43}=3.41, p<.001\right)$. There was no difference in mental QOL, in symptoms of anxiety and depression, in level of education and in optimism.

\section{INSERT HERE TABLE 2}

\subsection{Factor structure}

The item-total correlations for the 22 items ranged from -.06 to .73 , with a mean of .28 for the preliminary PE, and from .09 to .74 with a mean of .27 for the preliminary PH. Univariate normality was explored for the 22 items of preliminary PE and PH measures by calculating the skewness and kurtosis of each item for each measure. The results showed that skewness ranged from -.70 to 1.86 for preliminary $\mathrm{PE}$ and from -1.78 to 1.25 for preliminary $\mathrm{PH}$; while kurtosis ranged from -1.62 to 2.91 for preliminary $\mathrm{PE}$ and from -1.62 to 2.78 for preliminary $\mathrm{PH}$, indicating no strong deviation from normality (absolute values are considered to be extreme for skewness greater than 3 and kurtosis greater than 20; Weston \& Gore, 2006).

In order to classify items according to their level of abstraction (i.e., concrete vs. abstract), the correlation matrix was analyzed with an EFA computed with two factors, using the maximum likelihood method (as the data were normally distributed), and an orthogonal rotation (assuming that the factors were not correlated). The KMO measure of sampling adequacy and Bartlett's test of sphericity indicated that the 22 items of the preliminary PE measure were adequate for factor analysis $\left(\mathrm{KMO}=.73\right.$, Bartlett's $\left.\chi^{2}=613.37, p<.0001\right)$.

This EFA explained $39 \%$ of the total variance (factor $1=20 \%$ and factor $2=19 \%$ ). Based on a factor loading cut off of .40, factor 1 included items 3, 4, 5, 7, 9, 12, 14 and 17, and factor 2 
encompassed items 1, 10, 11, 13, 15, 19, 20 and 22 (see Table 3). It should be noted that item 22 has been included in factor 2 , despite a factor loading of .37 , in order to have the same number of items in the two factors (i.e. $n=8$ ) and since it loaded unambiguously on factor 2. Items 2,8 and 6 loading values were below .35 and were consequently excluded. Items 16, 18 and 21 loaded equally in the two factors and were therefore excluded. Thus, the factor 1 was labeled Abstract domains; items loading on this factor relate to the notion of self-identity and social/relational life. Factor 2 was labeled Concrete domains; items loading on this factor relate to functional aspects of everyday life and physical health.

\section{INSERT HERE TABLE 3}

\subsection{Reliability and construct validity}

Cronbach's alphas indicated good to acceptable internal consistency for all the PHEQ measures (PE-Total score: .88; PE-Concrete: .79; PE-Abstract: .87; PH-Total score: .88; PHConcrete: .77; PH-Abstract: .87). Pearson's correlations were first computed in order to examine inter-correlations between the PE-Total score, the PH-Total score and AS measure. These analyses revealed that the measures of expectations and hope are highly correlated with each other $(r=.82, p<.001 ; 95 \% \mathrm{CI}: 0.71,0.90)$, consistent with the idea that they are linked constructs. AS-Total score was negatively related to both expectations $(r=-.31, p=.03 ; 95 \% \mathrm{CI}$ : $-0.54,-0.04)$ and hope $(r=-.50, p<.001 ; 95 \% \mathrm{CI}:-0.69,-0.26)$, supporting the idea that dissatisfaction regarding AS may lead to increased expectations and desire of substantial changes following neurosurgery. Pearson's correlation analyses also revealed that age was moderately related to both expectations $(r=.37, p=.008 ; 95 \% \mathrm{CI}: 0.11,0.59)$ and hope $(r=.36, p=.009$; 
95\%CI: 0.10, 0.58). There was no relationship between the PHEQ measures and the level of education $(p \mathrm{~s}>.170)$. There was no gender effect on PHEQ measures ( $p$ s >.315).

Finally, Pearson's correlations computed to examine convergent validity revealed that generalized optimism was related to both expectations $(r=.43, p=.002 ; 95 \% \mathrm{CI}: 0.17,0.63)$ and hope $(r=.51, p<.001 ; 95 \% \mathrm{CI}: 0.26,0.69)$, which is consistent with previous studies (Leung et al., 2009). There was no correlation between depression and anxiety dimensions of the HADS and the PHEQ measures $(r \mathrm{~s}<.22, p \mathrm{~s}>.58)$. Finally, the physical QOL dimension (PCS) of the MOS-SF was negatively correlated to both expectations $(r=-.53, p<.001 ; 95 \% \mathrm{CI}:-0.71,-0.28)$ and hope $(r=-.39, p=.008 ; 95 \% \mathrm{CI}:-0.61,-0.11)$ measures. The mental QOL (MCS) was negatively associated with PH $(r=-.43, p=.003$; 95\% CI: $-0.64,-0.16)$ but not with PE $(r=-.21$, $p=.170 ; 95 \% \mathrm{CI}:-0.47,0.09)$.

Considering the potentially confounding influences of the intercorrelations between all the variables of interest, zero-order correlations cannot determine the independent contribution of each measure (i.e. once the effect of the other variables has been removed). Hence, to investigate the specific relationship between PHEQ measures (PE-Total score, PH-Total score) and the other variables of interest (age, AS assessment, HADS mood measures, mental and physical QOL and optimism), two regression analyses were performed. The THEQ measures were used as dependent variables, and age, AS-Total score, HADS-A, HADS-D, MOS-SF-PCS, MOS-SFMCS and LOT-Optimism as independent variables, using the backward exclusion selection procedure. As can be seen in Table 4, optimism and physical QOL emerged as significant independent predictors of PE-Total score, whereas optimism, AS measure and depression symptoms were significant independent predictors of the PH-Total score.

Specific relationships between expectations and hope and the other variables of interest were also examined, by taking the level of abstraction of life domains into account. In this 
prospect, four additional regression analyses have been performed, with PE-Abstract, $\mathrm{PH}$ Abstract, PE-Concrete and PH-Concrete as dependent variables, and age, HADS-A, HADS-D, MOS-SF-PCS-, MOS-SF-MCS, LOT-Optimism and AS-Total score as independent variables, using the backward exclusion selection procedure. As can be seen in Table 4, age, actual state, optimism and depression symptoms emerged as significant independent predictors of $\mathrm{PH}-$

Abstract, whereas optimism and age were significant independent predictors of the PE-Abstract. Optimism and mental QOL emerged as significant independent predictors of the PH-Concrete, whereas physical QOL and optimism were significant independent predictors of the PE-Concrete. INSERT HERE TABLE 4

\subsection{Group comparisons}

Future oriented cognitions across the two groups of patients were explored by means of a 2 (Type of content: Hope, Expectations) $\times 2$ (Level of content: Concrete, Abstract) $\times 2$ (Type of neurosurgery: DBS vs. ATL) mixed-design ANOVA. A main effect of type of content was observed suggesting that patients candidates for neurosurgery expressed higher desire of changes than realistic expectations regarding the outcome of surgery $F(1,48)=44.56, p<.001, \eta^{2}=.48$ (a small to medium effect size, according to Cohen's criteria; Cohen, 2013). There was also a main effect of group, suggesting that patients with PD expressed overall higher hope and expectations as compared to patients with epilepsy, $F(1,48)=6.57, p=.013, \eta^{2}=.12$ (a small effect size, according to Cohen's criteria), while there was no interaction Group $\times$ Type of content. The main effect of level of content was significant, suggesting that patients expressed hope and desire predominantly regarding concrete aspects of QOL, $F(1,48)=118.81, p<.001, \eta^{2}=.71(\mathrm{a}$ medium to large effect size, according to Cohen's criteria). The interaction Type of content $\times$ Level of content was significant, $F(1,48)=5.93, p<.019, \eta^{2}=.11$ (a small effect size, according 
to Cohen's criteria). This interaction effect, which has been further examined by means of Bonferroni post hoc tests, suggests that all PHEQ subscores were significantly different (see Table 2) with $\mathrm{PH}$ Concrete $>\mathrm{PE}$ Concrete $>\mathrm{PH}$ Abstract $>$ PE Abstract. There was also an interaction Group $x$ Level of content $F(1,48)=26.19, p<.001, \eta^{2}=.35$ (a small to medium effect size, according to Cohen's criteria). Bonferroni post hoc tests suggest the two groups had comparable levels of concrete representations but PD patients had significantly higher abstract representations as compared ATL patients $(p<.001)$ (see Figure 1). Finally, there was no triple interaction Type of content x Level of content x Group.

\section{INSERT HERE FIGURE 1}

\section{Discussion}

The aim of this study was to develop a tool assessing future-oriented cognitions in the context of functional neurosurgery, by examining separately two types of preoperative cognitions (hope vs. realistic expectations) and the level of representations (concrete such as independence in everyday life and symptom reduction vs. abstract such as psychological and interpersonal well-being). The results can be summarized as follows.

First, the results suggested that the PHEQ is a reliable instrument with satisfying psychometric properties. Previous findings regarding the relationships between preoperative representations and dispositional optimism (Alarcon et al., 2013) have been replicated in the present study. The pattern of correlations observed in this study further support the idea that hope and expectations are two distinct, although linked constructs (Leung et al., 2009). More specifically, expectations were highly correlated with hope, but these two constructs showed distinct patterns of associations with other measures. Indeed, lower preoperative expectations were associated with low optimism and high physical QOL, while low preoperative hope was 
specially associated with high actual state, low optimism and high depression symptoms. These findings support the idea that patients exhibiting depressive attitudes tend to demonstrate hopelessness (Rose et al., 1995). Statistical analyses further suggest that factors influencing preoperative future-oriented cognitions may also depend on the level of representations. Indeed, high abstract hope was predicted by age, AS, depression symptoms and optimism, while abstract expectations were predicted by age and dispositional optimism. On the other hand, optimism and mental QOL predicted concrete hope while optimism and physical QOL predicted concrete expectations.

Results also showed that patients candidates for neurosurgery had preoperative representations of outcomes that were more attuned towards concrete aspects of life. They also reported hope for improvement of their QOL that was significantly higher than realistic expectations. This suggests that they may experience strong desires for substantial changes following neurosurgery that may, at the same time, be perceived as poorly probable. Such discrepancies between desire of outcomes and evaluation of the probability that such outcomes may occur might interfere with postoperative adjustments process. It is also worth mentioning that patients with PD expressed overall higher hope and expectations than patients with epilepsy. Thus, future-oriented cognition may be determined by the type of diagnostic or surgery (DBS vs ATL). Future studies should be conducted in order to refine these results.

Before concluding, some limitations of the present study should be emphasized. First, the nature of the relationships found between the PHEQ and the other related constructs should be further refined, as the potential confounding effect of other factors, such as cognition, disease severity or duration were not controlled for, although patients with severe cognitive deficits were excluded during selection for DBS or ATL (based on a cutoff score of 130 on the Mattis Dementia Rating Scale). It is noteworthy that an important factor that potentially affects 
presurgical expectations has not been explicitly controlled in this study, namely the attitude of practitioners in providing information related to surgery. For instance, the extent to which a neurologist delivers an optimistic perspective or highlights predominantly potential benefits vs. a realistic perspective focused on risks and adverse effects, may affect the way candidates will perceive the outcomes. It should be noted however that in our study information was given to the candidates by means of a standardized brochure which fully explained all surgery aspects and by the neurologist's explanations that were putatively comparable from one candidate to another. Further studies as well as health care providers should take the aforementioned parameter into account. Finally, although this tool appears to be reliable and may help patients in anticipating potential psychosocial maladjustments, it remains to confirm its complex factor structure by means of a confirmatory factor analysis in a new but comparable sample.

\section{Conclusions}

On the basis of our findings, the PHEQ can be recommended to assess preoperative expectations and hope in patients candidates for functional neurosurgery. A better characterization of particular features of preoperative expectations may help clinicians to better understand what is important for their patients and enhance their adherence to treatment. Moreover, measuring changes in or fulfillment of expectations and their impact on satisfaction and clinical outcomes may help clinicians to optimize treatment strategies. Importantly, implementing tailored preoperative preparation consisting of cognitive restructuration of unsuitable expectations may prevent adverse events, thereby improving postoperative psychosocial adjustment and QOL.

\section{List of abbreviations}

$$
\text { AS, Actual State }
$$

ATL, Anterior temporal lobectomy 
BON, Burden of normality

DBS, Deep brain stimulation

HADS, Hospital Anxiety and Depression Scale

HADS-A, Hospital Anxiety and Depression Scale - Anxiety

HADS-D, Hospital Anxiety and Depression Scale - Depression

KMO, Kaiser-Meyer-Olkin

LOT, Life Orientation Test Revised

MCS, Mental Component Summary score

MOS-SF-36, Medical Outcome Study Short Form

PCS, Physical Component Summary score

PD, Parkinson's disease

PE, Preoperative Expectations

PH, Preoperative Hope

PHEQ, The Preoperative Hope and Expectation Questionnaire

QOL, Quality of life

UPDRS, Unified Parkinson's Disease Rating Scale III

\section{Declarations}

\section{Ethics approval and consent to participate}

The present study complies with the Code of Ethics of the World Medical Association

(Declaration of Helsinki, version 2004) and was approved by the Geneva Research Ethics

Committee CCER (approval 14-182). Informed consent was obtained from all patients participating in this study.

Consent for publication.

Informed consent for publication was obtained from all patients enrolled in the study. 


\section{Availability of data and materials}

The de-identified data that support the findings of this study are available on the Figshare repository https://doi.org/10.6084/m9.figshare.14522778.v2.

\section{Competing interests}

The authors declare that they have no competing interests.

\section{Funding}

This work was supported by the Swiss National Science Foundation under Grant number CR31I3_149578/1. The funding body did not affect the design of the study, the collection, analysis, and interpretation of data or the manuscript.

\section{Authors' contributions}

The authors confirm contribution to the paper as follows: study conception and design: M.R., J.F.A.D.S., K.W., M.B., P.R.B., F.H., A.C.; data collection: M.R., M.B., J.F.A.D.S.; analysis and interpretation of results: M.R., S.B., F.H.; draft manuscript preparation: M.R.; substantive revision of the work: N.F., P.R.B., A.C.; all authors reviewed the results and approved the final version of the manuscript.

\section{Acknowledgements}

Not applicable.

\section{References}

Agid, Y., Schüpbach, M., Gargiulo, M., Mallet, L., Houeto, J. L., Behar, C., Maltête, D., Mesnage, V., \& Welter, M. L. (2006). Neurosurgery in Parkinson's disease: the doctor is happy, the patient less so? Journal of Neural Transmission. Supplementum, 70(70), 409414.

Alarcon, G. M., Bowling, N. A., \& Khazon, S. (2013). Great expectations: A meta-analytic examination of optimism and hope. Personality and Individual Differences, 54, 821-827. 
https://doi.org/10.1016/j.paid.2012.12.004

Albrecht, G., \& Higgins, P. (1977). Rehabilitation Success: The Interrelationships of Multiple Criteria. Journal of Health and Social Behavior, 18(1), 36-45.

Baca, C. B., Cheng, E. M., Spencer, S. S., Vassar, S., \& Vickrey, B. G. (2009). Racial differences in patient expectations prior to resective epilepsy surgery. Epilepsy and Behavior, 15, 452455. https://doi.org/10.1016/j.yebeh.2009.05.010

Baxendale, S. A., \& Thompson, P. J. (1996). “If I Didn’t Have Epilepsy ...”: Patient Expectations of Epilepsy Surgery. Journal of Epilepsy, 9(4), 274-281. https://doi.org/10.1016/S0896-6974(96)00028-X

Bell, E., Maxwell, B., McAndrews, M. P., Sadikot, A. F., \& Racine, E. (2011). A review of social and relational aspects of deep brain stimulation in Parkinson's disease informed by healthcare provider experiences. Parkinson's Disease, 2011. https://doi.org/10.4061/2011/871874

Bell, E., Maxwell, B., McAndrews, M. P., Sadikot, A., \& Racine, E. (2010). Hope and patients' expectations in deep brain stimulation: healthcare providers' perspectives and approaches. The Journal of Clinical Ethics, 21(2), 112-124.

Bladin, P. F. (1992). Psychosocial difficulties and outcome after temporal lobectomy. Epilepsia, 33, 898-907. https://doi.org/10.1111/j.1528-1157.1992.tb02198.x

Cohen, J. (2013). Statistical Power Analysis for the Behavioral Sciences. In Statistical Power Analysis for the Behavioral Sciences. https://doi.org/10.4324/9780203771587

Constantino, M. J., Arnkoff, D. B., Glass, C. R., Ametrano, R. M., \& Smith, J. Z. (2011). Expectations. Journal of Clinical Psychology, 67, 184-192. https://doi.org/10.1002/jclp.20754

Fahn, S. E., \& Elton, R. (1987). The Unified Parkinson's Disease Rating Scale. Recent 
Developments in Parkinson's Disease Vol 2.

473 Gilbert, F. (2012). The burden of normality: from "chronically ill" to "symptom free". New

$474 \quad$ ethical challenges for deep brain stimulation postoperative treatment. Journal of Medical

475 Ethics, 38(7), 408-412. https://doi.org/10.1136/medethics-2011-100044

476 Gonzalez Saenz de Tejada, M., Escobar, A., Herrera, C., García, L., Aizpuru, F., \& Sarasqueta,

477 C. (2010). Patient expectations and health-related quality of life outcomes following total

$478 \quad$ joint replacement. Value in Health: The Journal of the International Society for

479

480

481

482

483

Hasegawa, H., Samuel, M., Douiri, A., \& Ashkan, K. (2014). Patients’ Expectations in Subthalamic Nucleus Deep Brain Stimulation Surgery for Parkinson Disease. World Neurosurgery.

Kline, P. (2014). An Easy Guide to Factor Analysis. Routledge. https://doi.org/10.4324/9781315788135

Lee, S. Y., \& Song, X. Y. (2004). Evaluation of the Bayesian and maximum likelihood approaches in analyzing structural equation models with small sample sizes. In Multivariate Behavioral Research. https://doi.org/10.1207/s15327906mbr3904_4

Leplège, A., Ecosse, E., Verdier, A., \& Perneger, T. V. (1998). The French SF-36 Health Survey: Translation, cultural adaptation and preliminary psychometric evaluation. Journal of Clinical Epidemiology. https://doi.org/10.1016/S0895-4356(98)00093-6

Leung, K. K., Silvius, J. L., Pimlott, N., Dalziel, W., \& Drummond, N. (2009). Why health expectations and hopes are different: The development of a conceptual model. Health Expectations, 12(4), 347-360. https://doi.org/10.1111/j.1369-7625.2009.00570.x

Maier, F., Lewis, C. J., Horstkoetter, N., Eggers, C., Kalbe, E., Maarouf, M., Kuhn, J., Zurowski, 

M., Moro, E., \& Woopen, C. (2013). Patients' expectations of deep brain stimulation, and subjective perceived outcome related to clinical measures in Parkinson's disease: a mixedmethod approach. Journal of Neurology, Neurosurgery \& Psychiatry, 84(11), 1273-1281.

Mancuso, C. A., Altchek, D. W., Craig, E. V, Jones, E. C., Robbins, L., Warren, R. F., \& Williams-Russo, P. (2002). Patients' expectations of shoulder surgery. Journal of Shoulder and Elbow Surgery, 11(6), 541-549.

Mancuso, C. A., Sculco, T. P., Wickiewicz, T. L., Jones, E. C., Robbins, L., Warren, R. F., \& Williams-Russo, P. (2001). Patients' expectations of knee surgery. The Journal of Bone \& Joint Surgery, 83(7), 1005-1012.

Mondloch, M. V, Cole, D. C., \& Frank, J. W. (2001). Does how you do depend on how you think you'll do? A systematic review of the evidence for a relation between patients' recovery expectations and health outcomes. CMAJ, 165, 174-179.

Montel, S. R., \& Bungener, C. (2009). Coping and quality of life of patients with Parkinson disease who have undergone deep brain stimulation of the subthalamic nucleus. Surgical Neurology, 72(2), 105-111. https://doi.org/10.1016/j.surneu.2008.05.026

Nisenzon, A. N., Robinson, M. E., Bowers, D., Banou, E., Malaty, I. A., \& Okun, M. S. (2011). Measurement of patient-centered outcomes in Parkinson's disease: what do patients really want from their treatment? Parkinsonism \& Related Disorders, 17(2), 89-94. https://doi.org/10.1016/j.parkreldis.2010.09.005

Reddy, P., Martinez-Martin, P., Brown, R. G., Chaudhuri, K. R., Lin, J.-P., Selway, R., Forgacs, I., Ashkan, K., \& Samuel, M. (2014). Perceptions of symptoms and expectations of advanced therapy for Parkinson's disease: preliminary report of a Patient-Reported Outcome tool for Advanced Parkinson's disease (PRO-APD). Health and Quality of Life Outcomes, 12, 11. https://doi.org/10.1186/1477-7525-12-11 
Rose, K. J., Derry, P. A., \& McLachlan, R. S. (1995). Patient expectations and postoperative depression, anxiety, and psychosocial adjustment after temporal lobectomy: a prospective study. International Journal of Behavioral Medicine, 2, 27-40. https://doi.org/10.1207/s15327558ijbm0201_3

Salgado, P. C. B., Fernandes, P. T., \& Cendes, F. (2008). Pre-surgery expectations and postsurgery life-changing validation process. Epileptic Disorders, 10, 290-296. https://doi.org/10.1684/epd.2008.0219

Schüpbach, M., Gargiulo, M., Welter, M. L., Mallet, L., Béhar, C., Houeto, J. L., Maltête, D., Mesnage, V., \& Agid, Y. (2006). Neurosurgery in Parkinson disease: A distressed mind in a repaired body? In Neurology (Vol. 66, pp. 1811-1816). https://doi.org/10.1212/01.wnl.0000234880.51322.16

Sherman, K. J., Eaves, E. R., Ritenbaugh, C., Hsu, C., Cherkin, D. C., \& Turner, J. A. (2014). Cognitive interviews guide design of a new CAM patient expectations questionnaire. $B M C$ Complementary and Alternative Medicine, 14, 39. https://doi.org/10.1186/1472-6882-14-39

Taenzer, P., Melzack, R., \& Jeans, M. E. (1986). Influence of psychological factors on postoperative pain, mood and analgesic requirements. Pain, 24, 331-342.

Törnqvist, A. L., Ahlström, G., Widner, H., \& Rehncrona, S. (2007). Fulfilment of patients' goals after thalamic deep brain stimulation: A follow-up study. Parkinsonism and Related Disorders, 13, 29-34. https://doi.org/10.1016/j.parkreldis.2006.06.005

Trottier, C., Trudel, P., Mageau, G., \& Halliwell, W. R. (2008). Validation de la version canadienne-française du Life Orientation Test-Revised. Canadian Journal of Behavioural Science, 40, 238-243. https://doi.org/10.1037/a0013244

Uhlmann, R., Inui, T., \& Carter, W. (1984). Patient Requests and Expectations Definitions and Clinical Applications. Medical Care. 
Weaver, F., Follett, K., Hur, K., Ippolito, D., \& Stern, M. (2005). Deep brain stimulation in Parkinson disease: a metaanalysis of patient outcomes. Journal of Neurosurgery, 103(6), 956-967.

Weston, R., \& Gore, P. A. (2006). A Brief Guide to Structural Equation Modeling. The Counseling Psychologist, 34(5), 719-751. https://doi.org/10.1177/0011000006286345

Wheelock, I., Peterson, C., \& Buchtel, H. A. (1998). Presurgery expectations, postsurgery satisfaction, and psychosocial adjustment after epilepsy surgery. Epilepsia, 39, 487-494. https://doi.org/10.1111/j.1528-1157.1998.tb01410.x

Wilson, S. J. (2001). The "burden of normality": concepts of adjustment after surgery for seizures. Journal of Neurology, Neurosurgery \& Psychiatry, 70(5), 649-656. https://doi.org/10.1136/jnnp.70.5.649

Wilson, S. J., Bladin, P. F., \& Saling, M. M. (2007). The burden of normality: a framework for rehabilitation after epilepsy surgery. Epilepsia, 48 Suppl 9, 13-16. https://doi.org/10.1111/j.1528-1167.2007.01393.x

Wilson, S. J., Saling, M. M., Kincade, P., \& Bladin, P. F. (1998). Patient expectations of temporal lobe surgery. Epilepsia, 39(2), 167-174. https://doi.org/10.1111/j.15281157.1998.tb01354.x

Wilson, S. J., Saling, M. M., Lawrence, J. A., \& Bladin, P. F. (1999). Outcome of temporal lobectomy: Expectations and the prediction of perceived success. Epilepsy Research, 36, 114. https://doi.org/10.1016/S0920-1211(99)00016-9

Zigmond, A. S., \& Snaith, R. P. (1983). The hospital anxiety and depression scale. Acta Psychiatrica Scandinavica, 67(6), 361-370. https://doi.org/10.1111/j.16000447.1983.tb09716.x 
Table 1. Characteristics of reviewed studies exploring expectations of patients candidates for functional neurosurgery (DBS and ATL).

\begin{tabular}{|c|c|c|c|c|}
\hline Authors & Surgery & Sample & Method & Domain of assessed preoperative representations \\
\hline Reddy et al., (2014) & DBS & 22 patients with PD & $\begin{array}{l}\text { Ad hoc questionnaire: Patient Reported Outcomes in Advanced Parkinson's } \\
\text { disease scale (PRO-APD) } \\
\text { Patients were asked to rate for each question: } \\
\text { (1) the symptom severity, (2) the expectation for change after therapy: }-3 \\
\text { (expected to be very much worse), to }+3 \text { (expected to be very much improved). }\end{array}$ & $\begin{array}{l}\text { Motor domain: tremor, stiffness, off periods, dyskinesia, freezing, dystonia, speech, balance } \\
\text { Non-motor domain: swallowing, sleep, bowels, bladder, pain, fatigue, sexual function } \\
\text { Cognitive/psychological domain: concentration, memory, impulsive behavior, hallucinations/psychosis, } \\
\text { mood, anxiety, apathy } \\
\text { Social and ADL: self-care, work, leisure/hobbies, socializing }\end{array}$ \\
\hline Maier et al., (2013) & DBS & 30 patients with $\mathrm{PD}$ & Semi-structured interview regarding preoperative expectations & $\begin{array}{l}\text { Health: motor improvement, reduction of medication, improvement of walking, improvement of tremor, less } \\
\text { dyskinesia, improvement of general health } \\
\text { ADL: carry out hobbies, car driving, trips, travels, } \\
\text { Social: more socializing, improvement of partnership } \\
\text { - Psychological: improvement of quality of life, improvement of mental state }\end{array}$ \\
\hline $\begin{array}{l}\text { Nisenzon et al., } \\
\text { (2011) }\end{array}$ & DBS & 148 patients with $\mathrm{PD}$ & $\begin{array}{l}\text { Modified version of the Patient-Centered Outcomes Questionnaire (PCOQ- } \\
\text { PD), patients were asked to rate for each domain: } \\
\text { (1) Usual levels of difficulty over the past week, (2) success criteria, (3) } \\
\text { expectations, (4) importance }\end{array}$ & $\begin{array}{l}10 \text { motor and non-motor functional domains } \\
\text { Health: Pain, fatigue, tremor, stiffness in limbs, slowness in movement, walking problems, sleep } \\
-\quad \text { Pychological: Emotional distress, thinking } \\
\text { - } \quad \text { ALL: Interference with daily activities (work, leisure) }\end{array}$ \\
\hline Törnqvist et al., (2007) & DBS & $\begin{array}{l}8 \text { patients with } \\
\text { essential tremor } \\
8 \text { patients with PD }\end{array}$ & $\begin{array}{l}\text { Semi-structured interview } \\
\text { Standardized open questions: What motor/social activities can you perform } \\
\text { today/ would you like to be able to perform when your tremor has decreased? }\end{array}$ & $\begin{array}{l}\text { Definition of personal goals related to symptoms commonly reduced by the treatment } \\
-\quad \text { Motor activity: housekeeping, hygiene, eating and drinking, writing, working, leisure activities } \\
\text { Social activity: being with other people, participating in social activities }\end{array}$ \\
\hline Bower et al., (2009) & ATL & $\begin{array}{l}389 \text { patients with } \\
\text { epilepsy }\end{array}$ & $\begin{array}{l}\text { Ad hoc questionnaire based on the literature and clinical experience } \\
12 \text { items, each item rated on a scale from } 1 \text { (not at all important) to } 10 \\
\text { (extremely important) }\end{array}$ & $\begin{array}{l}\text { ADL: driving limitations, limitations in bicycling, swimming, other physical activities } \\
\text { Social: participation in social situations } \\
\text { Health: level of fatigue, cosmetic physical aspects, pregnancy concerns, having to take epilepsy } \\
\text { medications } \\
\text { Psychological: emotional well-being, memory problems, language problems, concentration or attention } \\
\text { problems, economic worries }\end{array}$ \\
\hline Baca et al., (2009) & ATL & $\begin{array}{l}396 \text { patients with } \\
\text { epilepsy }\end{array}$ & $\begin{array}{l}\text { Interview } \\
\text { Open-ended questions about expectations for surgical outcome } \\
\text { - "In what ways do you feel limited by your epiless??" } \\
\text { - "What do you most hope to change as a result of this surgery?" }\end{array}$ & $\begin{array}{l}\text { - Expectations endorsed by }>15 \% \text { of the sample: driving, job/school, independence, seizure cessation, } \\
\text { social functioning, quality of life, medication discontinuance, physical activities, cognition } \\
\text { Expectations endorsed by less than } 15 \% \text { o the sample: embarrassment/stigma, emotional, fatigue, } \\
\text { general health, family planning, and no limitation }\end{array}$ \\
\hline $\begin{array}{l}\text { Salgado, Fernandes } \\
\text { and Cendes, (2008) }\end{array}$ & ATL & $\begin{array}{l}73 \text { patients with } \\
\text { epilepsy before } \\
\text { surgery } \\
63 \text { patients with } \\
\text { epilepsy after surgery }\end{array}$ & $\begin{array}{l}\text { Validation of the pre-surgery expectations questionnaire } \\
18 \text { yes/no questions }\end{array}$ & $\begin{array}{l}\text { Health: take less anti-epileptic medication, be healthy } \\
\text { ADL: drive, work or study, take care of my house / of my family, have fun, be safe to hang out alone } \\
\text { Social: have children, improve my social life, marry, improve my sexual life, be accepted by my family } \\
\text { Psychological: improve my memory, be happy, be less worried, feel free, be less nervous, feel ordinary }\end{array}$ \\
\hline Wheelock, (1998) & ATL & $\begin{array}{l}32 \text { patients with } \\
\text { epilepsy } \\
17 \text { significant others }\end{array}$ & $\begin{array}{l}\text { Semi-structured Interview about Epilepsy Surgery (SIAES) } \\
\text { (1) Ways in which seizure elimination would affect the patient's relationships } \\
\text { with significant others } \\
\text { (2) ...would be a good or positive change } \\
\text { (3)...would be a difficult or negative change }\end{array}$ & $\begin{array}{l}\text { - Have more friends, be less dependent, others will worry less, marital and family relations will improve } \\
\text { Be able to drive, to work, continue education, do more activities, mood improvement, risk of injury or } \\
\text { accident eliminated, reduces medication, anxiety eliminated, not feel as seek, not feel tired } \\
\text { Negative side effects of surgery, less attentions of others, face new responsibilities, no longer need of } \\
\text { significant other }\end{array}$ \\
\hline Wilson et al., (1998) & ATL & $\begin{array}{l}60 \text { patients with } \\
\text { epilepsy }\end{array}$ & $\begin{array}{l}\text { Standardized, semi-structured clinical interview } \\
\text { (1) What is the main reason you have sought surgical intervention? } \\
\text { (2) Do you see the operation as a chance to change your life? } \\
\text { (3) Have you made any postoperative plans? } \\
\text { (4) Do you plan on engaging in any new activities/ hobbies postoperatively? }\end{array}$ & $\begin{array}{l}\text { Expectations of surgery } \\
-\quad \text { Health: seizure ablation, medication } \\
-\quad \text { ADL: driving, employment, independence, new activities } \\
-\quad \text { Psychological: self change, general improvement } \\
-\quad \text { Social: family, relationships }\end{array}$ \\
\hline $\begin{array}{l}\text { Rose, Derry and } \\
\text { McLachlan, (1995) }\end{array}$ & ATL & $\begin{array}{l}17 \text { patients with } \\
\text { epilepsy }\end{array}$ & $\begin{array}{l}\text { Ad hoc questionnaire } \\
\text { The Epilepsy Expectations Questionnaire (EEQ) } \\
\text { Responses are based on future expectations }(1 \text { year), rated on a 7-point Likert- } \\
\text { type scale ranging from } 1 \text { (I do not expect this) to } 7 \text { (I very strongly expect this) }\end{array}$ & $\begin{array}{l}20 \text { questions assessing: } \\
-\quad \text { Physical health, epilepsy medication, seizure frequency } \\
-\quad \text { Mood, quality of life } \\
\text { Social adjustment } \\
\text { - Driving, occupation }\end{array}$ \\
\hline
\end{tabular}

Note. $\mathrm{PD}=$ Parkinson's Disease, $\mathrm{DBS}=$ Deep Brain Stimulation, ATL = Anterior Temporal Lobectomy, ADL = Activities of Daily Living. 
Table 2. Demographic and clinical characteristics of Patients in the entire sample and in each group (epilepsy and Parkinson's Disease (PD)).

\begin{tabular}{|c|c|c|c|}
\hline \multirow[b]{2}{*}{ Dependent variables } & \multirow[b]{2}{*}{ Whole sample $(n=50)$} & \multicolumn{2}{|c|}{ Groups of patients } \\
\hline & & Epilepsy $(n=25)$ & $\mathrm{PD}(n=25)$ \\
\hline Age & $46.16(17.05)$ & $32.72(12.75)$ & $59.60(7.41)$ \\
\hline Level of education & $12.57(4.26)$ & $12.00(2.83)$ & 13.33 (5.65) \\
\hline AS-Total score & 38.86 (8.66) & $42.08(8.55)$ & $35.64(7.64)$ \\
\hline PE-Total score & $21.00(11.38)$ & $17.12(8.53)$ & $24.88(12.66)$ \\
\hline PE-Concrete & $13.98(6.17)$ & $13.76(6.34)$ & $14.20(6.11)$ \\
\hline PE-Abstract & $7.02(6.66)$ & $3.36(3.16)$ & $10.68(7.31)$ \\
\hline PH-Total score & $28.04(13.00)$ & 23.92 (10.39) & $32.16(14.20)$ \\
\hline PH-Concrete & $18.08(6.45)$ & $17.84(6.30)$ & $18.32(6.73)$ \\
\hline PH-Abstract & $9.96(8.02)$ & $6.08(5.62)$ & $13.84(8.26)$ \\
\hline HADS-D & $5.47(3.24)$ & $4.83(3.26)$ & $6.13(3.15)$ \\
\hline HADS-A & $7.75(4.01)$ & $7.91(4.18)$ & $7.59(3.91)$ \\
\hline MOS-SF-PCS & 43.89 (10.95) & $51.48(7.68)$ & 35.95 (7.78) \\
\hline MOS-SF-MCS & 40.20 (9.69) & 40.69 (10.39) & 39.95 (9.11) \\
\hline LOT-Optimism & 16.66 (4.31) & 16.68 (4.59) & $16.64(4.11)$ \\
\hline
\end{tabular}

Note. $\mathrm{PE}=$ Preoperative expectations, $\mathrm{PH}=$ Preoperative Hope, $\mathrm{HADS}-\mathrm{A}=$ Hospital Anxiety and Depression Scale - Anxiety, HADS-D =

Hospital Anxiety and Depression Scale - Depression, MOS-SF-PCS = Medical Outcome Study - Short Form - Physical Component

Summary, MOS-SF-MCS = Medical Outcome Study - Short Form - Mental Component Summary, LOT = Life Orientation Test. 
Table 3. Factor loadings for the 22 items.

\begin{tabular}{|c|c|c|c|}
\hline \# & Item & Factor 1 & Factor 2 \\
\hline 1 & To be satisfied with my life & 0.15 & 0.48 \\
\hline 2 & To reduce symptoms of my disease & -0.08 & 0.01 \\
\hline 3 & To be independent in my personal care (e.g. hygiene, clothing) & 0.80 & 0.13 \\
\hline 4 & To feel good about myself & 0.43 & 0.31 \\
\hline 5 & To be satisfied with my relationship / romantic life & 0.52 & 0.39 \\
\hline 6 & To be able to travel alone (e.g. driving, taking public transport) & 0.30 & 0.15 \\
\hline 7 & To be satisfied with my physical appearance & 0.95 & 0.12 \\
\hline 8 & To get better sleep quality & 0.15 & 0.35 \\
\hline 9 & To be satisfied with my social life (family, friends) & 0.58 & 0.48 \\
\hline 10 & To be able to achieve my projects & 0.17 & 0.45 \\
\hline 11 & To be able to participate in leisure activities (e.g. sports, travel) & 0.41 & 0.60 \\
\hline 12 & To feel more like myself & 0.63 & 0.26 \\
\hline 13 & To be satisfied with my intellectual functioning (e.g. concentration, memory) & 0.13 & 0.59 \\
\hline 14 & To be satisfied with my sex life & 0.42 & 0.33 \\
\hline 15 & To be able to work (professional activity, housework) & 0.30 & 0.57 \\
\hline 16 & To be like everyone else & 0.44 & 0.43 \\
\hline 17 & Not to experience negative feelings (e.g. sad, anxious) & 0.51 & 0.37 \\
\hline 18 & To feel comfortable in social situations (e.g. outings, parties) & 0.50 & 0.60 \\
\hline 19 & To be able to enjoy life & 0.21 & 0.74 \\
\hline 20 & To be less tired, have more energy & 0.18 & 0.58 \\
\hline 21 & To reduce physical pain & 0.39 & 0.39 \\
\hline 22 & To get off medications & -0.19 & 0.37 \\
\hline
\end{tabular}

Note. Values greater than .40 are in bold. 
Table 4. Standardized regression coefficients, $t$ and $p$ values. for the variables of interest regressed on expectations and hopes measures.

\begin{tabular}{|c|c|c|c|c|c|c|c|c|c|c|c|c|c|c|c|c|c|c|c|c|c|}
\hline \multirow[b]{3}{*}{$\begin{array}{l}\text { Independent } \\
\text { variables }\end{array}$} & \multicolumn{21}{|c|}{ Dependent variables } \\
\hline & \multicolumn{3}{|c|}{ Age } & \multicolumn{3}{|c|}{ AS-Total score } & \multicolumn{3}{|c|}{ HADS-A } & \multicolumn{3}{|c|}{ HADS-D } & \multicolumn{3}{|c|}{ MOS-SF-PCS } & \multicolumn{3}{|c|}{ MOS-SF-MCS } & \multicolumn{3}{|c|}{ LOT-Optimism } \\
\hline & $\beta$ & $\mathrm{t}$ & $\mathrm{p}$ & $\beta$ & $\mathrm{t}$ & $\mathrm{p}$ & $\beta$ & $\mathrm{t}$ & $\mathrm{p}$ & $\beta$ & $\mathrm{t}$ & $\mathrm{p}$ & $\beta$ & $\mathrm{t}$ & $\mathrm{p}$ & $\beta$ & $\mathrm{t}$ & $\mathrm{p}$ & $\beta$ & $\mathrm{t}$ & $\mathrm{p}$ \\
\hline PH-Total score & .27 & 2.55 & .015 & -.52 & -2.61 & .013 & & NS & & -.24 & -2.13 & .040 & & NS & & & NS & & .52 & 5.26 & $<.000$ \\
\hline PE-Total score & & NS & & & NS & & & NS & & & NS & & -.353 & -2.36 & .023 & & NS & & .41 & 3.57 & $<.001$ \\
\hline PH-Concrete & & NS & & & NS & & & NS & & & NS & & & NS & & -.41 & -2.64 & .012 & .39 & 3.35 & .002 \\
\hline PH-Abstract & .41 & 3.90 & .001 & -.35 & -2.98 & .005 & & NS & & -.24 & -2.13 & .039 & & NS & & & NS & & .50 & 5.06 & $<.001$ \\
\hline PE-Concrete & & NS & & & NS & & & NS & & & NS & & -.32 & -2.42 & .020 & & NS & & .36 & 2.70 & .010 \\
\hline PE-Abstract & .31 & 2.33 & .025 & & NS & & & NS & & & NS & & & NS & & & NS & & .37 & 3.43 & .001 \\
\hline
\end{tabular}

Note. Bold values indicate predictors significant at $p<.05$. NS $=$ non-significant.

$\mathrm{PE}=$ preoperative expectations, $\mathrm{PH}=$ preoperative hopes. 


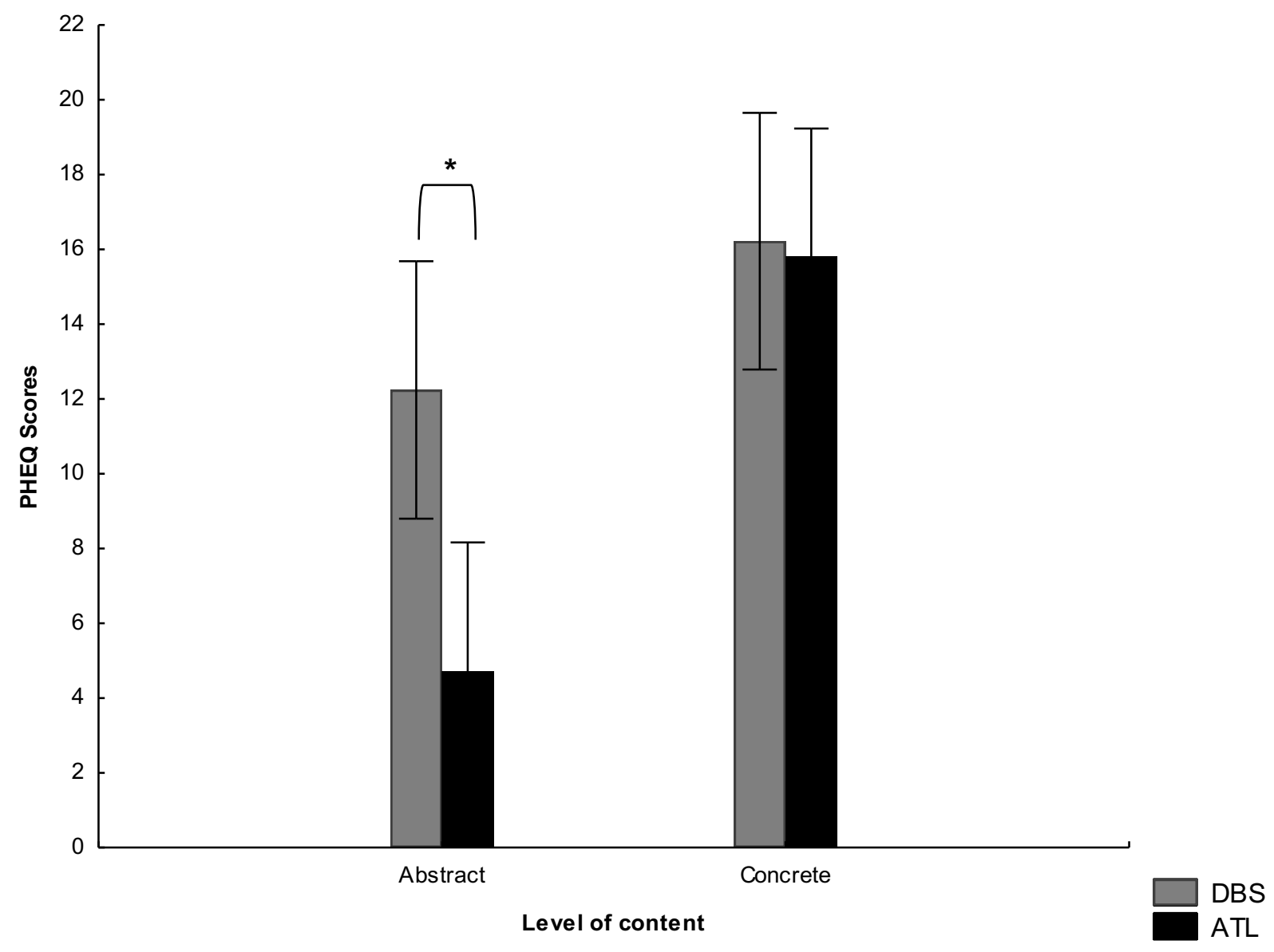

Figure 1. Interaction between Group and Level of content.

* = significant mean differences. 